\title{
Differential Effect of SdhB Gene Mutations on the Sensitivity to SDHI Fungicides in Botrytis cinerea
}

\author{
Thomas Veloukas, Aristotelian University of Thessaloniki, School of Agriculture, Laboratory of Plant Pathology, Thessaloniki, \\ Greece; Anastasios N. Markoglou, Agricultural University of Athens, Pesticide Science Laboratory, 11855 Athens, Greece; and \\ George S. Karaoglanidis, University of Thessaloniki, School of Agriculture, Laboratory of Plant Pathology
}

\begin{abstract}
Veloukas, T., Markoglou, A. N., and Karaoglanidis, G. S. 2013. Differential effect of SdhB gene mutations on the sensitivity to SDHI fungicides in Botrytis cinerea. Plant Dis. 97:118-122.

Succinate dehydrogenase inhibiting (SDHI) fungicides constitute a relatively novel fungicide group used for gray mold control caused mainly by Botrytis cinerea. Shortly after registration, resistance was observed in fungal populations that correlated with several mutations in the succinate dehydrogenase complex (complex II). In the current study, $30 \mathrm{~B}$. cinerea isolates possessing five different mutations at three different codons of $S d h \mathrm{~B}(\mathrm{P} 225 \mathrm{~F}, \mathrm{~N} 230 \mathrm{I}$, and $\mathrm{H} 272 \mathrm{~L} / \mathrm{R} / \mathrm{Y})$ were characterized for their sensitivities to eight SDHI fungicides. The results show different sensitivities and cross-resistance patterns between structurally different SDHIs. P225F mutants were resistant in vitro to all SDHIs tested. Similarly, isolates possessing the H272L mutation were highly resistant to boscalid but showed low to moderate levels of resistance to other SDHIs. The N230I mutants were moderately resistant to boscalid, fluopyram, and fluxapyroxad and showed low resistance

levels to isopyrazam, bixafen, fenfuram, benodanil, and carboxin. The H272R mutants showed moderate levels of resistance to boscalid and low resistance levels to isopyrazam, fenfuram, and carboxin but remained sensitive to fluopyram, bixafen, fluxapyroxad, and benodanil Similarly, the H272Y showed moderate levels of resistance to boscalid and very low resistance levels to isopyrazam, bixafen, fenfuram, and carboxin but showed increased sensitivity to benodanil and fluopyram. Boscalid provided moderate to high control of H272R/Y and N230I mutants in detached fruit assays but provided little control against the H272L and P225F mutants. In contrast, fluopyram controlled $\mathrm{H} 272 \mathrm{R} / \mathrm{Y}$ mutants and provided moderate levels of control toward H272L, N230I, and P225F mutants. Our findings suggest that sensitivity to SDHIs may vary greatly, dependent on the point mutation in the sdhb subunit.
\end{abstract}

Gray mold caused by Botrytis cinerea Pers. (teleomorph Botryotinia fuckeliana) is among the most important diseases of several crops, causing significant yield losses worldwide (10). Prior to 2005 , in most parts of the world, chemical control of gray mold was mainly achieved by site-specific fungicides belonging to the benzimidazoles, dicarboximides, anilinopyrimidines, phenylpyrroles, and hydroxyanilides (22). In 2007, the mixture of pyraclostrobin, belonging to the quinone outside inhibitors, and boscalid, belonging to the succinate dehydrogenase inhibitors (SDHIs), was registered in Greece and used in rotation with the above-mentioned fungicides for the control of the disease. Newer molecules belonging to the SDHI group such as fluopyram or penthiopyrad are expected to be available for the control of gray mold in the near future $(14,34)$.

SDHIs constitute an old fungicide group because the first generation of molecules belonging to this class (carboxin and its relatives) was introduced into the market in late 1960s for exclusive use against basidiomycetes. The discovery of new molecules for this fungicide class broadened the biological spectrum and increased the relevance of this fungicide class in crop protection (14). As of today, the SDHIs include seven different chemical groups with 15 different molecules (13). These fungicides have a common site-specific mode of action consisting of the inhibition of the cytochrome $b_{560}$ subunit of the succinate dehydrogenase complex (SDH, complex II) in the mitochondrial respiratory chain, also known as succinate:quinone oxidoreductase (8). This enzyme complex is an essential component of the mitochondrial electron

Corresponding author: G. S. Karaoglanidis,

E-mail: gkarao@agro.auth.gr

Accepted for publication 16 August 2012.

http://dx.doi.org/10.1094/PDIS-03-12-0322-RE

(c) 2013 The American Phytopathological Society transport pathway and of the tricarboxylic acid cycle, catalyzing both the oxidation of succinate to fumarate and the reduction of quinone, and its inhibition blocks cell energy production (25).

The risk for development of resistance to SDHIs has been assessed as moderate to high. Although cases of resistance to the first generation of molecules belonging in this class were rather restricted due to their limited activity spectrum, the cases of resistance to SDHIs rapidly increased after the introduction of boscalid for the control of several important diseases caused by ascomycetes and deuteromycetes. $(2,6,7,23,26)$. The mechanisms of resistance to SDHIs have been intensively studied using laboratory or field-mutants of several fungi. Resistance to SDHIs is mediated by single point mutations which lead to amino acid substitutions at $S d h \mathrm{~B}, S d h \mathrm{C}$, and $S d h \mathrm{D}$ subunits $(4,5,20,21,26)$. Regarding Botrytis cinerea, recent studies aiming to explore the mechanisms of resistance in SDHI-resistant field strains or laboratory mutants revealed that eight different amino acid modifications in $S d h \mathrm{~B}$ or $S d h \mathrm{D}$ subunit were associated with resistance to SDHIs $(9,11,23,35,36)$. Replacements of histidine by either tyrosine $(\mathrm{H} 272 \mathrm{Y})$ or arginine $(\mathrm{H} 272 \mathrm{R})$ at codon 272 of the $S d h \mathrm{~B}$ were the most frequent mutations detected in field isolates. A third mutation at the same codon, with the replacement of histidine by leucine $(\mathrm{H} 272 \mathrm{~L})$, has also been detected at low frequencies $(23,35)$. In addition, five more mutations have been described in the $S d h \mathrm{~B}$ subunit of B. cinerea. Three of them were located at codon 225 , leading to a substitution of proline by either phenylalanine $(\mathrm{P} 225 \mathrm{~F})$, threonine $(\mathrm{P} 225 \mathrm{~T})$, or leucine $(\mathrm{P} 225 \mathrm{~L})$, and one mutation was located at codon 230 , leading to an asparagine substitution by isoleucine (N230I) $(23,32,35)$. An additional mutation was detected in $S d h \mathrm{D}$ subunit, leading to histidine replacement by arginine at codon 132 (H132R) (23).

Despite the common mode of action of SDHI fungicides, there is strong evidence that these fungicides have different efficacy against resistant strains of Aspergillus oryzae, Corynespora cassiicola, and Podosphaera xanthii $(19,30)$. Thus, the characterization of the mutant genes conferring resistance to SDHIs would not only 
further clarify the molecular mechanisms of the inhibition effect of these fungicides but also elucidate the correlation between specific mutations and the inhibitory effect of these compounds. Based on the fact that SDHIs constitute a fungicide group with an increasing importance for the control of significant plant pathogens, including $B$. cinerea, the main objectives of the present study were to investigate the cross-resistance relationships among several SDHI fungicides among $B$. cinerea isolates possessing different $S d h$ mutations and to assess the impact of each mutation on the efficacy of boscalid or fluopyram in detached fruit assays. The knowledge of the impact of the $S d h$ mutations on the sensitivity of $B$. cinerea to SDHIs will provide a deeper understanding of the resistance risk to SDHIs and will assist in predicting or monitoring the development of resistance in the field.

\section{Materials and Methods}

Fungal isolates. Thirty $B$. cinerea isolates that had recently been characterized phenotypically and genotypically for resistance to boscalid and the associated $S d h \mathrm{~B}$ mutations (35) were used in the study. In all, 5 of the tested isolates were sensitive and 25 were resistant to the SDHI fungicide boscalid and possessed the P225F, N230I, H272L, H272R, or H272Y mutations (5 isolates per mutation). Isolates originated from strawberry fruit and had been collected from commercial or experimental fields between 2009 and 2011. The isolates were maintained on potato dextrose agar (PDA) slants at $4^{\circ} \mathrm{C}$

Fungicides. The fungicides used in this study were boscalid, benodanil, isopyrazam, carboxin, fluopyram, fenfuram, bixafen, and fluxapyroxad. All fungicides were pure technical grades purchased from Sigma-Aldrich, except fluopyram and fluxapyroxad, kindly supplied by Bayer CropScience and BASF Hellas, respectively. Fungicides were selected based on their chemical class, aiming to include at least one molecule from each chemical class of the SDHIs. Fungicide stock solutions were prepared in methanol. For the evaluation of boscalid and fluopyram in vivo, aqueous suspensions of the commercial product Cantus $50 \mathrm{WG}$ (boscalid at $500 \mathrm{~g}$ liter $^{-1}$; BASF) and a fluopyram experimental formulation (AE C656948 $500 \mathrm{SC}$, fluopyram at $500 \mathrm{~g} \mathrm{liter}^{-1}$; Bayer CropScience) were used.

Fungicide sensitivity assays. The sensitivity of $B$. cinerea isolates to SDHIs was tested on yeast-peptone-acetate (YBA) agar medium developed by Stammler and Speakman (33) and modified by Miyamoto et al. (26), containing $10 \mathrm{~g}$ of yeast extract, $10 \mathrm{~g}$ of Bacto peptone, $20 \mathrm{~g}$ of sodium acetate, and $15 \mathrm{~g}$ of agar per litter of medium. YBA agar medium was amended with the fungicides at concentrations of $0,0.001,0.005,0.01,0.05,0.1,0.5,1,5,10$, and $50 \mu \mathrm{g} \mathrm{ml}{ }^{-1}$. Spore suspensions for each isolate were prepared in sterile distilled water at a concentration of $1 \times 10^{5} \mathrm{ml}^{-1}$. Aliquots of the conidial suspensions were spread on fungicide-amended and fungicide-free 6-cm petri dishes. After $24 \mathrm{~h}$ of incubation at $22^{\circ} \mathrm{C}$, the germ tube length was measured in 20 spores per isolate and fungicide concentration.

Control efficacy of boscalid and fluopyram on strawberry fruit. Six $B$. cinerea isolates, one without $S d h$ gene mutations and five possessing either N230I, P225F, H272L, H272R, or H272Y, were selected for the experiment carried out to determine the efficacy of two SDHI fungicides in controlling the mutated isolates of the pathogen on strawberry fruit. The fungicides selected for the experiment were boscalid, which is already registered as a botryticide, and fluopyram, which is expected to be registered against $B$. cinerea. The fungicide concentrations applied were the commercially recommended doses for boscalid and fluopyram at 400 and $250 \mu \mathrm{g} \mathrm{ml}^{-1}$, respectively, and the half rate at 200 and $125 \mu \mathrm{g} \mathrm{ml}^{-1}$, respectively. The fruit were collected from an experimental strawberry field that had not received any fungicide treatment before. Fruit were collected at the stage of color change and selected on the basis of shape and size uniformity. Just after the arrival of the fruit into the laboratory, they were disinfected by immersion in 5\% ( $\mathrm{vol} / \mathrm{vol})$ sodium hypochlorite solution for $1 \mathrm{~min}$, rinsed three times in sterile deionized water, and subsequently air dried. Then, fruit were immersed in the fungicide suspensions for $30 \mathrm{~s}$. Control fruit were immersed in sterile tap water. Subsequently, fruit were air dried and transferred to the cold room for storage at $2^{\circ} \mathrm{C}$ until inoculation.

Artificial inoculation of the fruit was conducted $24 \mathrm{~h}$ after fungicide application. Inoculum was produced on PDA after 1 week of cultivation at $20^{\circ} \mathrm{C}$ under continuous light. The conidial suspensions were prepared in Gamborg minimal medium (3 $\mathrm{g}$ of Gamborg, $1.36 \mathrm{~g}$ of $\mathrm{KH}_{2} \mathrm{PO}_{4}$, and $9.9 \mathrm{~g}$ of glucose per litter of medium) and adjusted at a concentration of $2 \times 10^{5}$ spores $\mathrm{ml}^{-1}$. Inoculation was carried out by pipetting $20 \mu \mathrm{l}$ of a conidial suspension on two wounds inflicted near the fruit equator using a sterile fine needle. Fruit treated with sterile water were used as control. Then, fruit were placed on wire mesh platforms (20 fruits per box) in plastic boxes ( 23 by 31 by $10 \mathrm{~cm}$ [length by width by height]). Water ( 20 $\mathrm{ml}$ ) was added in each box and then the box was covered to maintain high relative humidity. Following inoculation, the fruit were incubated at $20^{\circ} \mathrm{C}$ for 5 days. At the end of the incubation period, the number of fruit showing decay symptoms was counted and disease severity was assessed by measuring the diameter of the rotting lesion around each wound. Twenty single-fruit replicates were used in each treatment and the experiment was repeated twice.

Data analysis. The fungicide concentration causing inhibition of germ tube growth by $50 \%$ ( $\mathrm{EC}_{50}$ value) for each isolate and fungicide was calculated by plotting the relative inhibition of germ tube length against the $\log _{10}$ of fungicide concentrations in the three replicates. The $\mathrm{EC}_{50}$ values for each isolate and fungicide tested were calculated from the data subjected to probit analysis. Resistance factors (RFs) were calculated by dividing the $\mathrm{EC}_{50}$ value for each isolate by the mean $\mathrm{EC}_{50}$ value of the sensitive ones. Based on the range of sensitivities, the isolates were grouped as sensitive $(\mathrm{RF}<2)$ or low (RF 3 to 10$)$, moderate (RF 10 to 100), or high $(\mathrm{RF}>100)$ in resistance. Analysis of variance was applied to the data of disease severity in the experiments carried out to determine the control efficacy of boscalid and fluopyram treatments against the $S d h \mathrm{~B}$ mutants of the pathogen. Lesion diameter data from the two repetitive experiments were combined after testing homogeneity of variance using the Levene's test $(P>0.05)$. Fischer's protected least significant difference test was used to determine significant differences between treatments. All the statistical analysis was supported by SAS (JMP; SAS Institute).

\section{Results}

Sensitivity to SDHIs. The ranges of $\mathrm{EC}_{50}$ values and the respective RFs within the groups of isolates tested are summarized in Table 1. Results showed variation regarding the intrinsic activity of the fungicides tested. The ranking of the intrinsic activities against $B$. cinerea, as indicated by the mean $\mathrm{EC}_{50}$ value for the group of the nonmutated isolates, was fluxapyroxad $>$ bixafen $>$ isopyrazam $>$ fluopyram $=$ boscalid $>$ carboxin $>$ benodanil $>$ fenfuram . Fluxapyroxad, bixafen, and isopyrazam were found to be two to three times more active than boscalid or fluopyram in vitro. The latter fungicides were nine times more active than carboxin, while benodanil and fenfuram showed very low intrinsic activity against B. cinerea.

Sensitivity measurements showed that isolates possessing the H272R mutation were of moderate resistance to boscalid, with RF values of 20 to 48 , but retained their sensitivity to fluopyram, fluxapyroxad, bixafen, and benodanil ( $R F=1$ to 2 ), suggesting an absence of cross-resistance relationships between these fungicides in $\mathrm{H} 272 \mathrm{R}$ mutant isolates. A low level of resistance $(\mathrm{RF}=3$ to 12 , based on $\mathrm{EC}_{50}$ ) to isopyrazam, fenfuram, and carboxin was observed in these resistant isolates.

The H272Y isolates were moderately resistant to boscalid and fluxapyroxad ( $\mathrm{RF}=18$ to 81 and 7.7 to 19.7 , respectively) and had a low level of resistance to isopyrazam, bixafen, fenfuram, and carboxin ( $\mathrm{RF}=2$ to 11$)$. Interestingly, these mutant strains were more susceptible than the sensitive ones to fluopyram and benodanil. 
The isolates possessing the $\mathrm{H} 272 \mathrm{~L}$ mutation showed high levels of resistance to boscalid, with an RF value $>555$; moderate resistance to fluopyram, fluxapyroxad, and carboxin, with RF values of 43, 69, and 47, respectively; and low levels of resistance to the remaining SDHI fungicides.

The isolates possessing the P225F mutation showed high levels of resistance to most of the fungicides tested, with $\mathrm{RF}$ values $>555$, 134 to 231,105 to 160 , and $>1,400$ for boscalid, fluopyram, bixafen, and fluxapyroxad, respectively. Moderate levels of resistance were observed for isopyrazam and carboxin, with RF values of 11 to 21 and 8 to 18 , respectively. Resistance levels were low for benodanil and fenfuram.

The N230I mutants were resistant to all fungicides tested, independently of their chemical structure, but significant differences in their resistance level were observed. These isolates were moderately resistant to boscalid, fluopyram, and fluxapyroxad, with RF values of 25 to 66,12 to 24 , and 15 to 23 , respectively. Resistance levels were low for isopyrazam and bixafen and the older carboxamides fenfuram, benodanil, and carboxin.

Control efficacy of boscalid and fluopyram on strawberry fruit. All resistant isolates tested retained their ability to cause infection on strawberry fruit (Table 2). However, there were marked differences in aggressiveness of some isolates as determined by lesion diameter. The results of preventive applications of boscalid and fluopyram against sensitive and resistant isolates are summarized in Table 2. Boscalid applications at either 200 or 400 $\mu \mathrm{g} \mathrm{ml}^{-1}$ controlled wild-type isolates by more than $97 \%$. Interestingly, boscalid applied at the commercially recommended dose of $400 \mu \mathrm{g} \mathrm{ml}^{-1}$ controlled N230I and H272R mutants by more than $70 \%$ but the $\mathrm{H} 272 \mathrm{Y}$ mutant was controlled only $47 \%$. Boscalid was completely ineffective in controlling the P225F and H272L mutants, even when applied at the commercially recommended dose, with control values of 11.5 and $12.4 \%$, respectively (Table 2). Fluopyram was as effective as boscalid in controlling the isolate of wild-type sensitivity. In addition, fluopyram applied at the commercially recommended dose of $250 \mu \mathrm{g} \mathrm{ml}^{-1}$ controlled completely the H272R and H272Y mutants but failed to control H272L and
P225F mutants. Disease severity, however, on fruit inoculated with the latter mutants and treated with fluopyram at $250 \mu \mathrm{g} \mathrm{ml}^{-1}$ was reduced by 68.2 and $44.8 \%$, respectively, compared with the untreated control (Table 2).

\section{Discussion}

In the current study, the impact of different $S d h \mathrm{~B}$ mutations on the sensitivity to several SDHI fungicides was determined in $B$. cinerea isolates. $\mathrm{SdhB}$ is an iron-sulfur protein subunit, consisting of three iron-sulfur centers: $2 \mathrm{Fe}-2 \mathrm{~S}(\mathrm{~S}-1), 4 \mathrm{Fe}-4 \mathrm{~S}(\mathrm{~S}-2)$, and $3 \mathrm{Fe}-$ $4 \mathrm{~S}$ (S-3) $(8,15-17)$. The sequence of the $S d h \mathrm{~B}$ subunit seems to be highly conserved among both eukaryotes and prokaryotes, indicating a common ancestor, whereas there is much greater variation in the sequence of the two membrane-spanning subunits $(S d h \mathrm{C}$ and $S d h \mathrm{D})(1,8)$. The results of our study showed that the chemical structure of the SDHIs is a significant factor affecting the sensitivity of $B$. cinerea isolates possessing different mutations in $S d h \mathrm{~B}$.

The P225F and N230I mutations have only been described in $B$. cinerea and $M$. graminicola $(12,14,23,29,35)$. Both mutations are located around the highly conserved tryptophane residue of the second iron-sulfur complex (4Fe-4S) of the $S d h \mathrm{~B}$ subunit (15). Several studies have shown that the tryptophane residue is part of the ubiquinone binding site (Q-site), a hydrophobic pocket formed by several residues in $\mathrm{B}, \mathrm{C}$, and $\mathrm{D}$ subunits $(16,18)$. In silico docking analysis and kinetic inhibitory studies with computational models have shown that carboximide fungicides bind on tryptophane residue by forming hydrogen bonds through their central amide moiety (14). The results of our study show that isolates possessing the proline replacement by phenylalanine at codon $225(\mathrm{P} 225 \mathrm{~F})$ were resistant in vitro to all SDHI fungicides tested. Furthermore, isolates possessing this mutation showed higher RFs for most of the fungicides tested. Interestingly, the higher RFs were observed in group members of newer generations such as the anilide-pyrazole carboxamides (bixafen and fluxapyroxad), the pyridinecarboxamides (boscalid), and the pyridinil-ethyl benzamides (fluopyram). Among the SDHIs of the newer generations, the lower RFs of P225F mutants were observed in isopyrazam. At the

Table 1. Sensitivity of Botrytis cinerea isolates carrying different mutations in succinate dehydrogenase (sdh)B gene to several succinate dehydrogenase inhibiting fungicides

\begin{tabular}{|c|c|c|c|c|c|c|c|c|c|c|c|c|c|c|c|c|}
\hline \multirow[b]{3}{*}{ Mutation } & \multicolumn{16}{|c|}{ Fungicide $^{\mathrm{z}}$} \\
\hline & \multicolumn{2}{|c|}{ Boscalid } & \multicolumn{2}{|c|}{ Fluopyram } & \multicolumn{2}{|c|}{ Isopyrazam } & \multicolumn{2}{|c|}{ Bixafen } & \multicolumn{2}{|c|}{ Fluxapyroxad } & \multicolumn{2}{|c|}{ Fenfuram } & \multicolumn{2}{|c|}{ Benodanil } & \multicolumn{2}{|c|}{ Carboxin } \\
\hline & $\mathbf{E C}_{50}$ & RF & $\mathbf{E C}_{50}$ & $\mathbf{R F}$ & $\mathbf{E C}_{50}$ & RF & $\mathbf{E C}_{50}$ & $\mathbf{R F}$ & $\mathbf{E C}_{50}$ & $\mathbf{R F}$ & $\mathbf{E C}_{\mathbf{5 0}}$ & RF & $\mathbf{E C}_{50}$ & $\mathbf{R F}$ & $\mathbf{E C}_{50}$ & RF \\
\hline Sensitive & $0.06-0.12$ & - & $0.08-0.12$ & - & $0.01-0.09$ & - & $0.03-0.07$ & - & $0.01-0.06$ & - & $3.36-9.25$ & - & $3.52-8.52$ & - & $0.80-0.94$ & - \\
\hline $\mathrm{H} 272 \mathrm{R}$ & $1.68-4.33$ & $18.6-48.1$ & $0.10-0.20$ & $1.1-2.2$ & $0.26-0.63$ & $5.2-12.6$ & $0.06-0.09$ & $1.5-2.2$ & $0.05-0.10$ & $1.4-2.8$ & $13.0-26.5$ & $2.3-4.7$ & $5.04-10.3$ & $0.9-1.9$ & $3.2-5.6$ & $4.2-6.7$ \\
\hline $\mathrm{H} 272 \mathrm{Y}$ & $1.68-7.30$ & $18.6-81.1$ & $0.03-0.08$ & $0.3-0.8$ & $0.20-0.55$ & $4.0-11.0$ & $0.16-0.32$ & $4.0-8.0$ & $0.27-0.69$ & $7.7-19.7$ & $9.6-34.8$ & $1.7-6.2$ & $1.37-4.17$ & $0.2-0.7$ & $3.85-8.25$ & $4.5-9.8$ \\
\hline $\mathrm{H} 272 \mathrm{~L}$ & $>50$ & $>555$ & $3.44-3.9$ & $38.2-43.3$ & $0.23-0.38$ & $4.6-7.6$ & $0.18-0.37$ & $4.5-9.2$ & $1.60-3.04$ & $45.7-86.8$ & $22.9-33.6$ & $4.0-6.0$ & $43.3-46.0$ & $7.8-8.3$ & $42.4-47.9$ & $50.4-57.0$ \\
\hline $\mathrm{P} 225 \mathrm{~F}$ & $>50$ & $>555$ & $13.1-20.8$ & $134-231$ & $0.60-1.04$ & $12.0-20.8$ & $4.22-6.40$ & $105-160$ & $>50$ & $>1400$ & $20.6-26.1$ & $3.6-4.6$ & $20.6-44.0$ & $3.7-8.0$ & $7.10-15.3$ & $8.4-18.2$ \\
\hline N230I & $2.21-5.96$ & $24.5-66.2$ & $1.10-2.15$ & $12.2-23.8$ & $0.20-0.39$ & $4.0-7.8$ & $0.25-0.33$ & $6.2-8.2$ & $0.48-0.80$ & $13.7-22.8$ & $18.1-32.3$ & $3.2-5.7$ & $8.9-19.7$ & $1.6-3.5$ & $3.89-7.75$ & $4.6-9.2$ \\
\hline
\end{tabular}

$\mathrm{z}$ Fungicide concentration causing inhibition of germ tube growth by $50 \%$ ( $\mathrm{EC}_{50}$ values) are given in micrograms per milliliter. Resistance factor (RF) values were calculated by dividing the isolate $\mathrm{EC}_{50}$ value by the mean $\mathrm{EC}_{50}$ values for the nonmutated isolates of $0.09,0.09,0.05,0.04,0.035,5.6,5.5$, and $0.84 \mu \mathrm{g} \mathrm{ml}^{-1}$ for boscalid, fluopyram, isopyrazam, bixafen, fluxapyroxad, fenfuram, benodanil, and carboxin, respectively.

Table 2. Disease incidence (DI), disease severity (DS), and control efficacy (CE) of succinate dehydrogenase inhibiting fungicide-resistant Botrytis cinerea on strawberry fruit treated with boscalid and fluopyram ${ }^{\mathrm{z}}$

\begin{tabular}{|c|c|c|c|c|c|c|c|c|c|c|c|c|c|c|c|}
\hline \multirow[b]{4}{*}{ Isolate } & & & & \multicolumn{12}{|c|}{ Fungicide } \\
\hline & & & & \multicolumn{6}{|c|}{ Boscalid } & \multicolumn{6}{|c|}{ Fluopyram } \\
\hline & \multicolumn{3}{|c|}{ Untreated control } & \multicolumn{3}{|c|}{$200 \mu \mathrm{g} \mathrm{ml}^{-1}$} & \multicolumn{3}{|c|}{$400 \mu \mathrm{g} \mathrm{ml}^{-1}$} & \multicolumn{3}{|c|}{$125 \mu \mathrm{g} \mathrm{ml}^{-1}$} & \multicolumn{3}{|c|}{$250 \mu \mathrm{g} \mathrm{ml}^{-1}$} \\
\hline & DI & DS & $\mathbf{C E}$ & DI & DS & $\mathbf{C E}$ & DI & DS & $\mathbf{C E}$ & DI & DS & $\mathbf{C E}$ & DI & DS & $\mathbf{C E}$ \\
\hline E8, wild-type & $40 \mathrm{a}$ & $18.5 \mathrm{a}$ & $\ldots$ & $10.0 \mathrm{a}$ & $0.5 \mathrm{~d}$ & 97.2 & $0.0 \mathrm{a}$ & $0.0 \mathrm{e}$ & 100.0 & $20.0 \mathrm{a}$ & $0.9 \mathrm{e}$ & 94.8 & $0.0 \mathrm{a}$ & $0.0 \mathrm{~d}$ & 100.0 \\
\hline L5.2, H272L & $40 \mathrm{a}$ & $13.8 \mathrm{bc}$ & $\ldots$ & $40.0 \mathrm{~b}$ & $14.1 \mathrm{a}$ & 0.0 & $40.0 \mathrm{c}$ & $12.1 \mathrm{a}$ & 12.4 & $40.0 \mathrm{~b}$ & $9.2 \mathrm{~b}$ & 33.3 & $40.0 \mathrm{c}$ & $4.4 \mathrm{~b}$ & 68.2 \\
\hline E14, H272R & $40 \mathrm{a}$ & $16.6 \mathrm{~b}$ & $\ldots$ & $40.0 \mathrm{~b}$ & $7.6 \mathrm{c}$ & 54.2 & $24.0 \mathrm{~b}$ & $3.4 \mathrm{~d}$ & 79.5 & $36.0 \mathrm{~b}$ & $4.3 \mathrm{c}$ & 73.7 & $0.0 \mathrm{a}$ & $0.0 \mathrm{~d}$ & 100.0 \\
\hline E12, H272Y & $40 \mathrm{a}$ & $11.5 \mathrm{c}$ & $\ldots$ & $40.0 \mathrm{~b}$ & $11.0 \mathrm{~b}$ & 4.4 & $36.0 \mathrm{c}$ & $6.1 \mathrm{c}$ & 47.0 & $22.0 \mathrm{a}$ & $2.7 \mathrm{~d}$ & 76.6 & $0.0 \mathrm{a}$ & $0.0 \mathrm{~d}$ & 100.0 \\
\hline $\mathrm{E} 22, \mathrm{P} 225 \mathrm{~F}$ & $40 \mathrm{a}$ & $9.5 \mathrm{c}$ & $\ldots$ & $40.0 \mathrm{~b}$ & $9.2 \mathrm{c}$ & 4.2 & $40.0 \mathrm{c}$ & $8.5 \mathrm{~b}$ & 11.5 & $40.0 \mathrm{~b}$ & $12.4 \mathrm{a}$ & 0.0 & $40.0 \mathrm{c}$ & $5.2 \mathrm{a}$ & 44.8 \\
\hline S20, N230I & $40 \mathrm{a}$ & $17.0 \mathrm{ab}$ & $\ldots$ & $40.0 \mathrm{~b}$ & $12.5 \mathrm{ab}$ & 26.1 & $40.0 \mathrm{c}$ & $4.6 \mathrm{~d}$ & 72.9 & $40.0 \mathrm{~b}$ & $4.7 \mathrm{c}$ & 72.3 & $24.0 \mathrm{~b}$ & $1.9 \mathrm{c}$ & 88.5 \\
\hline
\end{tabular}

${ }^{\mathrm{z}} \mathrm{DI}=$ total number of infected strawberry fruit after artificial inoculation, DS $=$ mean diameter of lesion per fruit counted on 40 strawberry fruit per treatment, and $\mathrm{CE}=$ percent control values, calculated as $100-[($ severity treated/severity untreated $) \times 100]$. Means followed by different letters in the column are significantly different according to Fisher's least significant difference test at $P=0.05$. 
same codon, two more mutations, consisting of the replacement of proline by threonine (P225T) or leucine (P225L), were recently reported in France conferring moderate and high levels of resistance, respectively, to boscalid (23). Such mutants have not been detected in Greece and, thus, were not included in the current study. The second mutation located around the tryptophane residue involving the replacement of asparagine by isoleucine at codon 230 (N230I) also conferred resistance to all fungicides tested in this study. Resistance levels were generally low, however, with the exception of boscalid, for which moderate levels of resistance were observed.

The remaining three mutations tested were all located at codon 272 of the $S d h \mathrm{~B}$ subunit, in which a histidine residue is encoded in isolates with wild-type sensitivity. This residue is located at the farthest point from the opening of the Q-site and, because SDHIs bind deeper than ubiquinone at this site, they are in direct contact with this residue through hydrogen bonding $(14,27)$. Such mutations have previously been shown to be the predominant mutations conferring resistance to SDHIs in phytopathogenic fungi, including $B$. cinerea $(3,23)$, as well as in other fungal and bacterial species $(24,25,31)$. Despite the fact that these mutations were located at the same codon, the results of our study showed that they differentially affect sensitivity to the SDHIs tested. The replacement of histidine by leucine (H272L) conferred resistance to all fungicides tested, independently of their chemical structure. Isolates possessing this mutation were highly resistant to boscalid and moderately resistant to fluopyram, fluxapyroxad, and carboxin. The level of resistance to the remaining fungicides, including the newer SDHIs such as isopyrazam and bixafen, was low. Isolates possessing the histidine replacement by arginine (H272R) showed moderate levels of resistance to boscalid whereas they were of wild-type sensitivity to fluopyram, bixafen, fluxapyroxad, and benodanil, suggesting an absence of cross-resistance relationship in these mutants. Resistance levels to the remaining fungicides such as isopyrazam, fenfuram, and carboxin were low in H272R mutants. Similarly, isolates possessing the histidine replacement by tyrosine at codon 272 (H272Y) showed moderate levels of resistance to boscalid whereas, to all of the remaining fungicides but fluopyram and benodanil, they showed only low levels of resistance. Interestingly, the H272Y mutants showed higher sensitivity to the benzamide derivatives fluopyram and benodanil compared with that of the wild-type isolates. This may be due to a better binding of fungicides possessing a benzamide ring in the Q-pocket of mutants possessing a histidine replacement by tyrosine at that codon. The increased sensitivity to benzamide fungicides in fungal strains possessing a histidine replacement by tyrosine (H272Y) has been previously reported for other fungal species such as Didymella bryoniae (6), C. cassiicola, P. xanthii (19), Mycosphaerella graminicola (29), and A. oryzae (30).

The level of resistance conferred by each mutation in $s d h \mathrm{~B}$ may have important implications on the performance of SDHI fungicides used against gray mold disease. In the current study, we evaluated the performance of two SDHI fungicides (boscalid, which is already in use against the disease, and fluopyram, which is scheduled be introduced into the market in the near future) in controlling the SDHB mutants. The in vitro sensitivity of the tested isolates to boscalid and fluopyram roughly correlated with the observed control efficacy achieved by the application of the same active ingredients at the commercially recommended doses on detached fruit. Boscalid provided very low levels of control efficacy against the two mutants possessing the H272L and P225F mutations, whereas control efficacy was low to moderate against the mutants possessing the H272R/Y and N230I mutations. H272R is the predominant mutation within the field populations of the pathogen in strawberry fields in Greece (35). Selection of this mutation at relatively high levels has not yet led to control failures in the field (T. Veloukas, unpublished data), which may be due to the moderate control efficacy of boscalid against H272R mutants, potential fitness penalties in $s d h \mathrm{~B}$ mutants, or low disease pressure. In contrast, fluopyram eliminated the $\mathrm{H} 272 \mathrm{R} / \mathrm{Y}$ mutants and pro- vided high control efficacy against the N230I mutant and moderate control efficacy against the H272L and P225F mutants. A similarly high control efficacy of fluopyram against fungal strains possessing histidine replacements by either tyrosine or arginine at the same codon have been observed in $P$. xanthii and $C$. cassiicola (19). The good performance of fluopyram against H272R/Y mutants in vivo suggests that these mutations do not confer resistance to the benzamide fungicides. Therefore, the introduction of fluopyram into field spray programs may eliminate H272R/Y mutants. However, frequent use of the new molecules may lead to changes in the mutation-type frequency by selection of mutants that show moderate or high levels of resistance (i.e., P225F, N230I, and H272L). Therefore, the alternation or simultaneous use of structurally different SDHIs might lead to the selection of fully crossresistant mutants (28).

The development of resistance to SDHIs in B. cinerea populations could cause significant problems for disease management because Sdh mutations may strongly affect the fungicide performance against the mutated strains, as indicated by the results of the current study. Maintaining the high efficacy of boscalid or other compounds belonging to the SDHI group that will be registered in the near future would be beneficial for successful disease management because resistance to alternative fungicide classes is already widespread in most regions of the world. A better understanding of factors that may affect the persistence of SDHI resistance in $B$. cinerea, such as the effect of each specific mutation on the fitness of the strains or the effect of fungicide spray programs applied in the field on the selection of each mutant, should be further investigated.

\section{Acknowledgments}

We thank BASF Hellas S.A. and Bayer CropScience Hellas A.G. for providing fluxapyroxad and fluopyram pure technical grade and the formulated products, respectively; and H. Lachaise (Bayer SAS, Bayer CropScience Primary Screening \& Biology Support, Centre de Recherche de La Dargoire, Lyon, France ) and G. Stammler (BASF Agro, Limburgerhoff, Germany) for critical reading of the manuscript and helpful suggestions.

\section{Literature Cited}

1. Ackrell, B. A. C. 2000. Progress in understanding structure-function relationships in respiratory chain complex II. FEBS Lett. 466:1-5.

2. Avenot, H. F., and Michailides, T. J. 2007. Resistance to boscalid fungicide in Alternaria alternata isolates from pistachio in California. Plant Dis. 91:1345-1350.

3. Avenot, H. F., and Michailides, T. J. 2010. Progress in understanding molecular mechanisms and evolution of resistance to succinate dehydrogenase inhibiting (SDHI) fungicides in phytopathogenic fungi. Crop Prot. 29:643-651.

4. Avenot, H. F., Sellam, A., Karaoglanidis, G., and Michailides, T. J. 2008 Characterization of mutations in the iron-sulphur subunit of succinate dehydrogenase correlating with boscalid resistance in Alternaria alternata from California pistachio. Phytopathology 98:736-742.

5. Avenot, H. F., Sellam, A., and, Michailides, T. J. 2009. Characterization of mutations in the membrane-anchored subunits AaSDHC and AaSDHD of succinate dehydrogenase from Alternaria alternata isolates conferring field resistance to the fungicide boscalid. Plant Pathol. 58:1134-1143.

6. Avenot, H. F., Thomas, A., Gitaitis, R. D., Langston, D. B., Jr., and Stevenson, K. L. 2012. Molecular characterization of boscalid- and penthiopyradresistant isolates of Didymella bryoniae and assessment of their sensitivity to fluopyram. Pest Manage. Sci. 68:645-651.

7. Bardas, G. A., Veloukas, T., Koutita, O., and Karaoglanidis, G. S. 2010 Multiple resistance of Botrytis cinerea from kiwifruit to SDHIs, QoIs and fungicides of other chemical groups. Pest Manage. Sci. 66:967-973.

8. Cecchini, G. 2003. Function and structure of complex II of the respiratory chain. Annu. Rev. Biochem. 72:77-109.

9. de Miccolis Angelini, R. M, Habib, W., Rotolo, C., Pollastro, S., and Faretra, F. 2010. Selection, characterization and genetic analysis of laboratory mutants of Botryotinia fuckeliana (Botrytis cinerea) resistant to the fungicide boscalid. Eur. J. Plant Pathol. 128:185-199.

10. Elad, Y., Williamson, B., Tudzynski, P., and Delen, N., 2004. Botrytis spp. and diseases they cause in agricultural ecosystems - an introduction. Pages 1-8 in: Botrytis: Biology, Pathology and Control. Y. Elad, B. Williamson, P. Tudzynski, and N. Delen, eds. Springer, Dordrecht, The Netherlands.

11. Fernandez-Ortuno, D., Chen, F., and Schnabel, G. 2012. Resistance to pyraclostrobin and boscalid in Botrytis cinerea isolates from strawberry in the Carolinas. Plant Dis. 96:1198-1203.

12. Fraaje, B. A., Bayon, C., Atkins, S., Cools, H. J., Lucas, J. A., and Fraaje, 
M. W. 2012. Risk assessment studies on succinate dehydrogenase inhibitors, the new weapons in the battle to control Septoria leaf blotch in wheat. Mol. Plant Pathol. 13:263-275.

13. FRAC. 2012. The FRAC List of Fungicide Common Names. Fungicide Resistance Action Committee. www.frac.info

14. Glättli, A., Stammler, G., Grote, T., and Schlehuber, S. 2011. SDH Inhibitors: History, biological performance and molecular mode of action. Pages 159-169 in: Modern Fungicides and Antifungal Compounds VI. H. W. Dehne, H. B. Deising, U. Gisi, K. H. Kuck, P. E. Russell, and H. Lyr, eds. DPG, Braunschweig, Germany.

15. Hagerhall, C. 1997. Succinate: quinone oxidoreductases variations in a conserved theme. Biochim. Biophys. Acta 1320:107-141.

16. Horsefield, R., Iwata, S., and Byrne, B. 2004. Complex II from a structural perspective. Curr. Protein Pept. Sci. 5:107-118.

17. Horsefield, R., Yankovskaya, V., Sexton, G., Whittingham, W., Shiomi, K., Omura, S., Byrne, B., Cecchini, G., and Iwata, S. 2006. Structural and computational analysis of the quinone-binding site of complex II (succinateubiquinone oxidoreductase) - a mechanism of electron transfer and proton conduction during ubiquinone reduction. J. Biol. Chem. 281:7309-7316.

18. Huang, L., Sun, G., Cobessi, D., Wang A. C., Shen J. T., Tung E. Y., Anderson, V. E., and Berry, E. A. 2006. 3-Nitropropionic acid is a suicide inhibitor of mitochondrial respiration that, upon oxidation by complex II, forms a covalent adduct with a catalytic base arginine in the active site of the enzyme. J. Biol. Chem. 281:5965-5972.

19. Ishii, H., Miyamoto, T., Ushio, S., and Kakishima, M, 2011. Lack of crossresistance to a novel succinate dehydrogenase inhibitor, fluopyram, in highly boscalid-resistant isolates of Corynespora cassiicola and Podosphaera xanthii. Pest Manage. Sci. 67:474-482.

20. Ito, Y., Muraguchi, H., Seshime, Y., Oita, S., and Yanagi, S. O. 2004. Flutolanil and carboxin resistance in Coprinus cinereus conferred by a mutation in the cytochrome b560 subunit of succinate dehydrogenase complex (complex II). Mol. Genet. Genomics 272:328-235.

21. Keon, J. P. R., White, G. A., and Hargreaves, J. A. 1991. Isolation, characterization and sequence of a gene conferring resistance to the systemic fungicide carboxin from the maize smut pathogen, Ustilago maydis. Curr. Genet. 19:475-481

22. Leroux, P. 2004. Chemical control of Botrytis and its resistance to chemical fungicides. Pages 195-222 in: Botrytis: Biology, Pathology and Control. Y. Elad, B. Williamson, P. Tudzynski, and N. Delen, eds. Springer, Dordrecht, The Netherlands.

23. Leroux, P., Gredt, M., Leroch, M., and Walker, A.-S. 2010. Exploring mechanisms of resistance to respiratory inhibitors in field strains of Botrytis cinerea, the causal agent of gray mold. Appl. Environ. Microbiol. 76:66156630.

24. Li, J., Zhou, M., Li, H., Chen, C., Wang, J., and Zhang, Y. 2006. A study on the molecular mechanism of resistance to amicarthiazol in Xanthomonas campestris pv. citri. Pest Manage. Sci. 62:440-445.

25. Matsson, M., and Hederstedt, L. 2001. The carboxin-binding site on Paracoccus denitrificans succinate:quinone reductase identified by mutations. J. Bioenerg. Biomembr. 33:99-105.

26. Miyamoto, T., Ishii, H., Stammler, G., Koch, A., Ogawara, T., Tomita, Y., Fountaine, J. M., Ushio, S., Seko, T., and Kobori, S. 2010. Distribution and molecular characterization of Corynespora cassiicola isolates resistant to boscalid. Plant Pathol. 59:873-881.

27. Ruprecht, J., Yankovskaya, V., Maklashina E., Iwata, S., and Cecchini, G. 2009. Structure of Escherichia coli succinate:quinone oxideructase with an occupied and empty quinone-binding site. J. Biol. Chem. 284:29836-29846.

28. Scalliet, G., Boehler, M., Bowler, J., Green, P. S., Kilby, P. M., and FonnePfister, R. 2011. SDHIs and the fungal succinate dehydrogenase. Pages 171178 in: Modern Fungicides and Antifungal Compounds VI. H. W. Dehne, H. B. Deising, U. Gisi, K. H. Kuck, P. E. Russell, and H. Lyr, eds. DPG, Braunschweig, Germany.

29. Scalliet, G., Bowler, J., Luksch, T., Kirchhofer-Allan, L., Steinhauer, D. Ward, K., Niklaus, M., Verras, A., Csukai, M., Daina, A., and Fonne-Pfister R. 2012. Mutagenesis and functional studies with succinate dehydrogenase inhibitors in the wheat pathogen Mycosphaerella graminicola. PLos One 7:e35429.

30. Shima, Y., Ito, Y., Hatabayashi, H., Koma, A., and Yabe, K. 2011. Five carboxin-resistant mutants exhibited various responses to carboxin and related fungicides. Biosci. Biotechnol. Biochem. 75:181-184.

31. Shima, Y., Ito, Y., Kaneko, S., Hatabayashi, H., Watanabe, Y., Adachi, Y., and Yabe, K. 2009. Identification of three mutant loci conferring carboxinresistance and development of a novel transformation system in Aspergillus oryzae. Fungal Genet. Biol. 46:67-76.

32. Stammler, G., Brix, H. D., Nave, B., Gold, R., and Schoefl, U. 2008. Studies on the biological performance of boscalid and its mode of action. Page 45-51 in: Modern Fungicides and Antifungal Compounds V. H. W. Dehne, H. B. Deising, U. Gisi, P. E. Russell, and H. Lyr, eds. DPG, Braunschweig, Germany.

33. Stammler, G., and Speakman, J. 2006. Microtiter method to test the sensitivity of Botrytis cinerea to boscalid. J. Phytopathol. 154:508-510.

34. Veloukas, T., and Karaoglanidis, G. S. 2012. Biological activity of the succinate dehydrogenase inhibitor fluopyram against Botrytis cinerea and fungal baseline sensitivity. Pest Manage. Sci. 68:858-864.

35. Veloukas, T., Leroch, M., Hahn, M., and Karaoglanidis, G. S. 2011. Detection and molecular characterization of boscalid-resistant Botrytis cinerea isolates from strawberry. Plant Dis. 95:1302-1307.

36. Yin, Y. N., Kim, Y. K., and Xiao, C. L. 2011. Molecular characterization of boscalid resistance in field isolates of Botrytis cinerea from apple. Phytopathology 101:986-995. 